\title{
ERA40 にもとづく日本列島周辺長期波浪データベースの構築
}

\author{
Long-Term Ocean Wave Database around Japanese Islands based on \\ Re-Analysis Meteorological Dataset ERA-40
}

\author{
小林智尚 ${ }^{1}$ ・佐々木博一 ${ }^{2} \cdot$ 吉野 $^{\text {純 }}{ }^{3} \cdot$ 安田孝志 $^{4}$
}

\author{
Tomonao KOBAYASHI, Hirokazu SASAKI, Jun YOSHINO and Takashi YASUDA
}

\begin{abstract}
Ocean wave database around Japanese islands for 45 years is build based on the meteorological dataset ERA-40, ECMWF 40 Years Re-Analysis. Since the ERA-40 is coarse for the wave hindcasting in the target domain, the mesoscale meteorological model MM5 was applied to evaluate the sea-surface wind at higher resolution; and, the wave model SWAN was employed to compute the long-term wave fields. The computed wave fields were successfully improved by applying the wind fields evaluated with MM5. The comparison of the wave database with the field observed data shows good agreement, and leads to the conclusion that the database is highly accurate.
\end{abstract}

\section{1.はじめに}

海岸・沿岸構造物の計画・設計等では波浪統計資料が 必要とされる機会が多い。しかし現状では長期に及ぶ波 浪データは定点観測が行われている地点にほぼ限られて おり，また期間も十分でない場合が多い。一方波浪推算 手法は近年数值モデルの開発・改良が進み, WAMに 代表される第三世代波浪推算モデルが活用できるように なり，精度の高い波浪場の再現が可能となっている. 現 在波浪推算手法は現地観測データが存在しない地域・期 間の波浪を追算するなど, 現地観測と並んで利用される までに至っている。

このような波浪推算手法を用いて定点観測のみでは不 十分であった長期間の波浪の再現解析も進められている. 山口ら (1997) は長期浅海波浪推算モデルを構築し, 約 10 年間の波浪推算を実施, その推算結果の妥当性を観 測結果と比较して示している．また川口ら(2002)は長期 間にわたる波浪推算を実施し，その結果を日本沿岸波浪 の出現特性として整理している.しかし現在, 日本全国 を網羅した数十年スケールの長期間データベースの構築 は見られない。これは波浪推算で必要となる長期間の海 上風データの入手がこれまで困難であったためである. しかし近年では NCEP (National Centers for Environmental Prediction) ゃ ECMWF (European Centre for Medium-Range Weather Forecasts）などで全球を対象

\footnotetext{
1 正会貝 博(工) 岐皇大学教授 工学研究科環境エネルギー システム専攻

2 岐阜大学大学院 工学研究科環境エネルギ ーシステム専玫

3 正会員 博(理) 岐皁大学助教 工学研究科環境エネルギー

4 フェロー 工博 岐皁大学教授 工学研究科環境エネルギー
}

とした気象解析が行われ，その結果が公開されている. そこで本研究では ECMWFにて解析された長期間の 全球気象再解析デー夕 ERA-40 (ECMWF 40 Year Re-Analysis）を用いて日本列島周辺の長期間波浪場を 再現し，データベースを構築した。ただしこの ERA-40 は全球を対象とした再解析データであるため日本列島周 辺を対象とした解析では時空間解像度が不十分である. そこでここでは局地気象モデル MM5を用いて ERA-40 からより高解像度な気象場を再現し，その結果を波浪推 算に用いた。

\section{2. 波浪場推定手法}

本研究では日本列島周辺域の長期間波浪データベース の構築を再解析気象データERA-40を元に行った。し かしこのERA-40は全球を対象とした再解析データで あるため, 緯度経度空間解像度 2.5 度, 時間解像度 6 時 間と，日本列島周辺海域の解析には解像度が不十分であ る.そこで本研究では局地気象モデル MM5を用いて日 本周辺域の高精度な気象場を再現し，さらに第三世代波 浪推算モデルSWANにより長期間波浪場を再現した。 以下に本研究で用いたデータおよび数值モデルについて 記す。

\section{（1）波浪場推定の流れ}

本研究では 45 年間の全球再解析気象データセットで あるERA-40をもとに領域気象モデル MM5を用いて 高精度の海上風場を再現している。そしてこの結果から 波浪推算モデルSWANを用いて日本列島周辺域の長期 間波浪データベースを構築している。この一連の流れを 図-1に示守。この図の通り，ERA-40を用いて日本列 島周辺域の気象場を MM5 で高精度に再現する。そして ERA-40の海上風データを用いた広域の波浪推算を SWAN で実施する，さらにネストダウンして日本列島 
周辺域の波浪推算を MM5 の解析結果を用いて実施する. 最後に波浪推算結果を日本列島周辺域長期波浪データベ ースとして保存・整備している.

\section{(2) 再解析気象データ ERA-40}

ERA-40 (ECMWF 40 Year Re-Analysis) は Uppala ら（2005）によって構築された長期間全球気象再解析デ 一タセットである、このデータセットは 1957 年 9 月か ら 2002 年 8 月まで 45 年間の長期間を, 緯度・経度解像 度 2.5 度, 時間解像度 6 時間, と高解像度で全球再解析 した結果であり，様々な気象要素を網羅している.

またこの再解析では波浪推算モデルによる全球波浪解 析も行っている.たたしこの波浪解析結果も空間解像度 2.5 度, 時間解像度 6 時間であり，日本列島周辺域を対 象とした波浪データベースとしては分解能が不十分であ る.そこで今回は改めて波浪推算モデル SWANを用い て再度解析を行い，高精度の時空間分解能を有する波浪 データベースを構築している。

\section{（3）局地気象モデル MM5}

日本列島周辺域での詳細な波浪推算を行うためには, 日本列島の沿岸地形を再現しうる程度の解像度を有する 海上風場のデータが必要となる．ERA-40の海上風デー 夕は日本列鳥周辺域を対象とした場合には時空間分解能 とも粗く，詳細な波浪推算を行うためにはより高解像度 のデータを必要とする.そこで本研究では緯度経度 2.5 度間隔， 6 時間間隔の ERA-40データセットをもとに局 地気象モデル MM5（Dudhia, 1993 ; Grell ら，1995） を用いて，円錐図法地図上で水平方向空間解像度 $50 \mathrm{~km}$ の解析を行った，そしてこの解析結果から, 緯度・経度 方向共に解像度 0.5 度, 時間間隔 1 時間の海上風データ を作成した。この解析結果は ERA-40に比べてより小 規模な気象現象や沿岸地形の影響を再現している。この ためこの解析結果を波浪推算に用いることにより，日本 列島周辺域ではより詳細な波浪場の推定が可能となった。

\section{（4）波浪推算モデル SWAN}

海洋波浪の推算には第三世代波浪推算モデル SWAN （Booij ら，1999）を用いた。実際に適用したモデルで

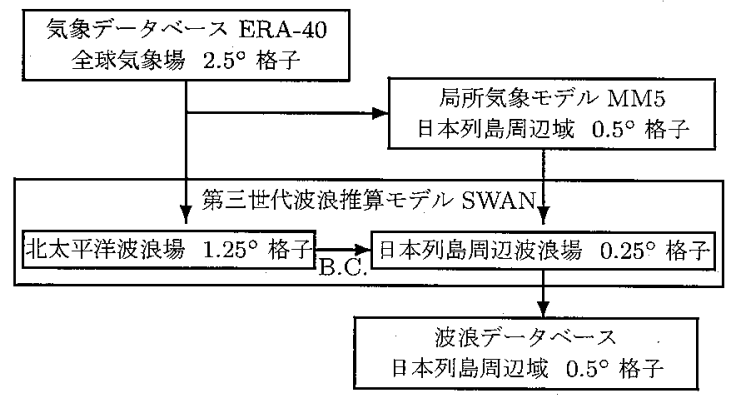

図-1＼cjkstart波浪データベース構築の流れ
表-1 波浪推算計算条件

\begin{tabular}{|c|c|c|}
\hline & 大領城 & 小領域 \\
\hline 対象領城 東経 & $\begin{array}{l}110^{\circ} \sim 240^{\circ} \\
-30^{\circ} \sim 70^{\circ}\end{array}$ & $\begin{aligned} & 120^{\circ} \sim 150^{\circ} \\
& 20^{\circ} \sim 50^{\circ}\end{aligned}$ \\
\hline 解析期間 & \multicolumn{2}{|c|}{1957 年 9 月〜 2002 年 8 月 } \\
\hline $\begin{array}{l}\text { 空間解像度 } \\
\text { (経度 } \times \text { 緯度) }\end{array}$ & $1.25^{\circ} \times 1.25^{\circ}$ & $0.25^{\circ} \times 0.25^{\circ}$ \\
\hline 時間解像度 & 1 時間 & 0.5 時間 \\
\hline $\begin{array}{l}\text { 海上風データ } \\
(10 \mathrm{~m} \text { 高度風速) }\end{array}$ & $\begin{array}{c}\text { ERA-40 データセット } \\
\left(2.5^{\circ} \times 2.5^{\circ}\right) \\
\end{array}$ & $\begin{array}{c}\text { MM5 解析データ } \\
\left(0.5^{\circ} \times 0.5^{\circ}\right) \\
\end{array}$ \\
\hline 境界条件 & $\begin{array}{c}\text { 閉境界 } \\
\end{array}$ & ネストダウン \\
\hline
\end{tabular}

表-2 日本列島周辺域長期波浪データベースの緒元

\begin{tabular}{|c|c|}
\hline 期 間 & 1957 年 9 月～ 2002 年 8 月 \\
\hline 領 & $\begin{array}{l}\text { 東経 } 120^{\circ} \sim 150^{\circ} \\
\text { 北緯 } 20^{\circ} \sim 50^{\circ}\end{array}$ \\
\hline 空間解像度 & $0.5^{\circ}$ (経度 $) \times 0.5^{\circ}$ (緯度 $)$ \\
\hline 時間解像度 & 1 時間 \\
\hline パラメータ & $\begin{array}{l}\text { 有義波高, 平均周期, 主波向, うねり成分波高, } \\
10 \mathrm{~m} \text { 高度風速 ·風向 }\end{array}$ \\
\hline
\end{tabular}

は，気象庁提供の海上風データを用いた試行計算を通し てパラメータを調整している. 本研究で用いる気象デー 夕は ERA-40をもとにした MM5 の解析結果であるが， ここでは気象打提供海上風デー夕を用いたパラメー夕調 整の結果をそのまま用いた。

本研究では图-1に示す通り，海上風データに ERA40 を用いて北太平洋を中心とした広い領域を対象とし た波浪推算を実行した徯に，ネストダウンして MM5 の 解析結果から得られた海上風デー夕を用いた日本列島周 辺域の波浪推算を実施した．推算条件を表-1に示す. また解析結果の一例として，伊勢湾台風が来龔した 1959 年 9 月 26 日 18 時における海上風速分布および有 義波高分布を図-2に示す，図中のベクトルは波向を示 している.

この波浪推算により得られる結果のうち，長期波浪デ 一タベースとして曰本列島周辺域における䋨度経度方向 0.5 度格子上での各種波浪パラメータを保存・整備した。 このデータベースの緒元を表-2に示す。

\section{3. 解析データの検証}

本研究では 1957 年 9 月から 2002 年 8 月までの長期間 波浪情報データベースを構築している。ここではこのデ ータベースの精度について検討する。

\section{（1）平面波浪場の再現性}

再解析気象データセットERA-40を，過去天気図と 比較してその再現性を確認する。

図-3に, 2001 年 8 月 20 日9時に招ける，日本列島周 辺域での海上風と有義波高の分布を天気図と共に示す. この時期, 天気図 (図 (c)) の通り台風 T0111 が九州南 方にあったが，ERA-40を元にした MM5 の解析結果 


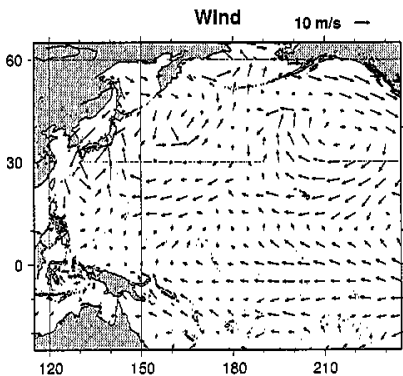

風速分布

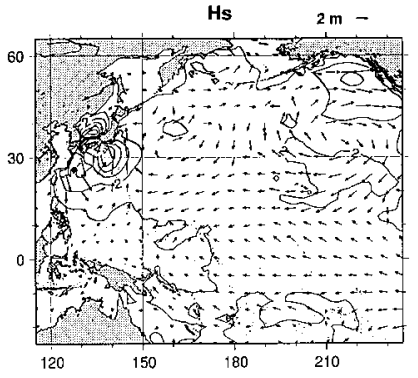

有㼁波高分布(単位：m)

(a) 大頒域

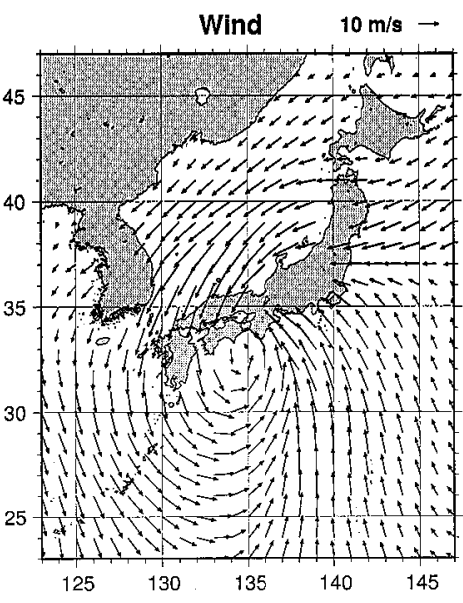

風速分布

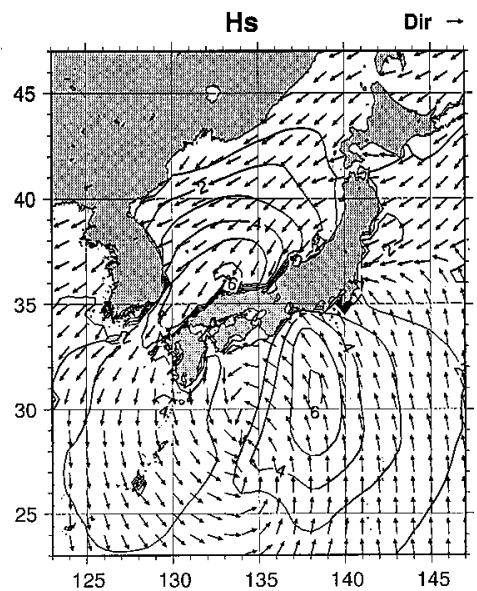

有義波高分布(単位：m)

(b) 小領域

図-2 波浪推算結果（1959 年 9 月 26 日 18 時）

(図 (a))でもこの台風による渦上の風域が明瞭に再現さ れており，ERA-40の解析結果は過去の気象を十分再現 していることがわかる。

次に御前崎における 2001 年 8 月の有義波高の時系列 変化を図-4に示す。図中，実線が小領域における波浪 推算結果を示しており，全国海洋波浪情報網（ナウファ ス，永井・小川，2003；港湾技術研究所）によって得ら れた波浪観测結果は丸印で示している，また，破線は大 領域における波浪推算結果であり，これについては後節 で議論する。この図では台風 T0111による高波浪が 8 月22日に観測されているが，推算結果においてはこの 観測結果を高い精度で再現している。この結果は ERA-40 から MM5 拉よび SWANを用いて解析した結 果ではあるが，この有義波高の再現性から基礎データで ある ERA-40が十分な精度を有していることが間接的 に確認できた。

\section{（2）時系列波浪場の再現性}

ここでは波浪データベースとしての精度について検討 を行う。この榆討では全国海洋波浪情報網によって得ら れた波浪観测結果とデータベースの推算結果とを比較し た。比較対象点は太平洋岸の御前崎と日本海側の輪島の 2 点とした。

夏季（2001 年 8 月）の輸島における推算結果を図-5 に，また冬季（2001 年 1 月）の御前崎, 輸島の結果を
図-6に示す。図中，実線が小領域における波浪推算結 果を示しており，観測結果は丸印で示している。また破 線は大領域における波浪推算結果でありこれについて は次節で議論する。図-4を加えたこれらの図から波浪 推算結果は高い精度で観測結果を再現していることがわ かる，しかし図-6(a)の様に推算結果の再現性が低い場 合も見られた。他の期間での検討も通して日本海側の輪 島での再現性が高い傾向が見られた。

次に 2001 年通年での波浪推算結果を観測値との相関 で㭘討した，図-7に御前崎および輪島における有義波 高の相関を示す．この図から御前崎では比較的低波浪時 に有義波高を過大に評価する傾向が見られる。一方，輸 島では高波浪時に有義波高を過大に評価する傾向がある ものの, 全体を通してその再現性は御前崎より高い。こ れは日本海のほほ全域が解析対象の小領域に含まれるた め, 海域全体の海上風が MM5によって高解像度に再現 でき，波浪推算ではこの海上風を用いて解析できたため， 特に日本海での解析では再現性が高かったと考えられる。

図-4 から図-7 までの結果を含めた解析結果全体から， 本研究で構築した波浪データベースは日本列島沿岸域の 波浪場を高い精度で再現してることが確認できた。

（3）気象場の高解像度解析による効果

本研究では日本列島周辺域の海上風を再解析気象デー 夕セットERA-40 からさらに局所気象モデル MM5を 


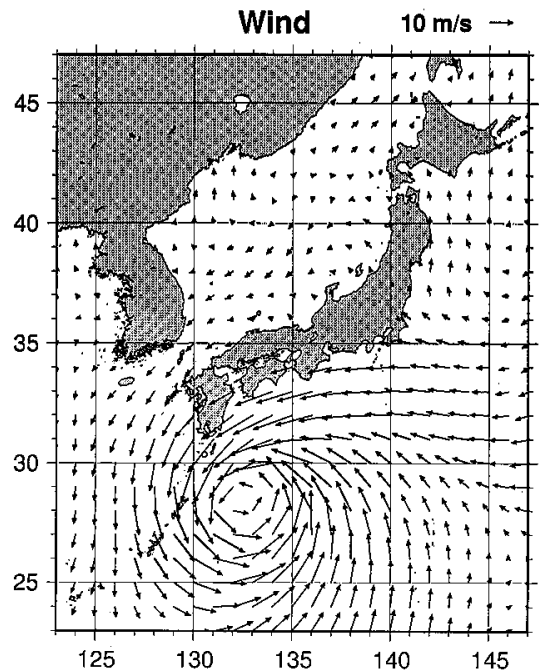

(a) 海上風分布 (MM5 解析結果)

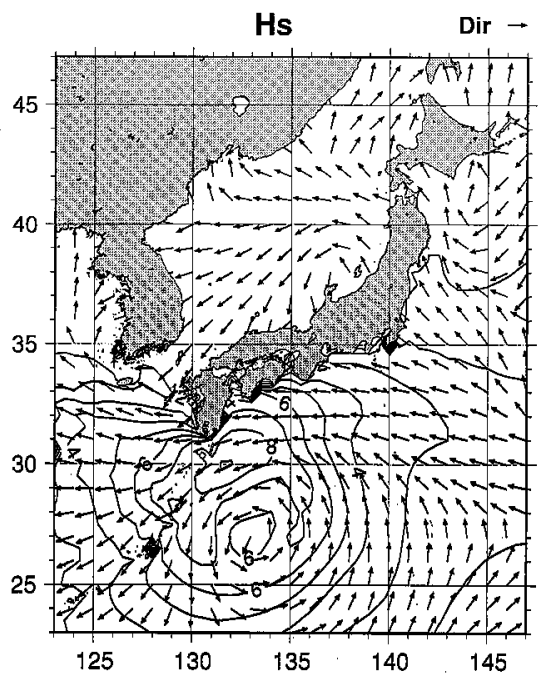

(b) 有義波高・波向分布 (SWAN 解析結果, $\mathrm{m}$ )

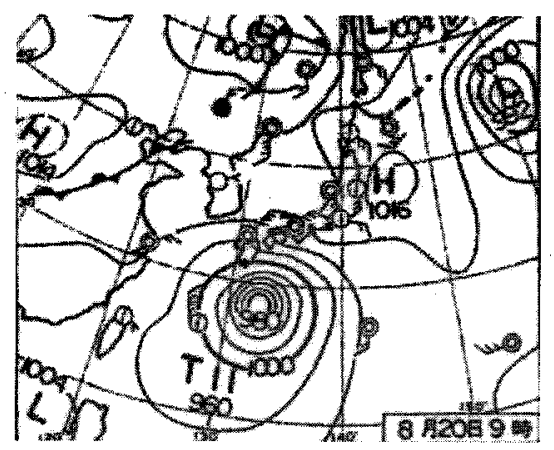

(c) 天気図（日本気象協会，2001）

図-3 ERA-40を元にした解析結果と天気図（2001 年 8 月 20 日 9 時)

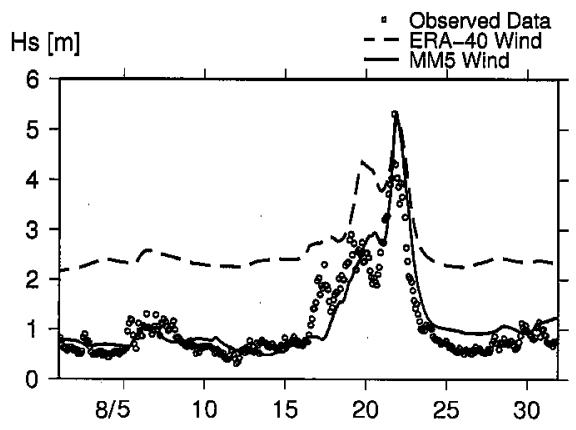

図-4 御前崎での有義波高変化（2001 年 8 月）

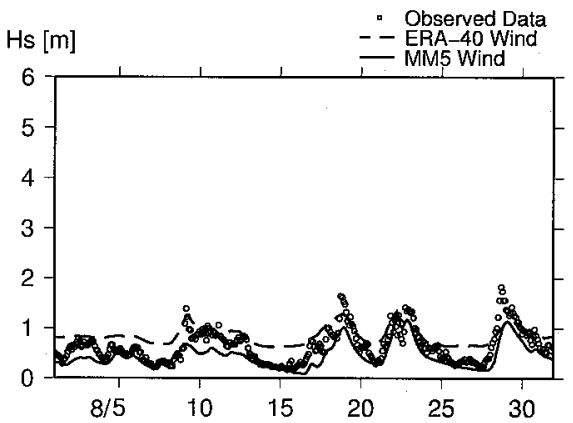

図-5＼cjkstart翰島での有義波高変化（2001 年 8 月）

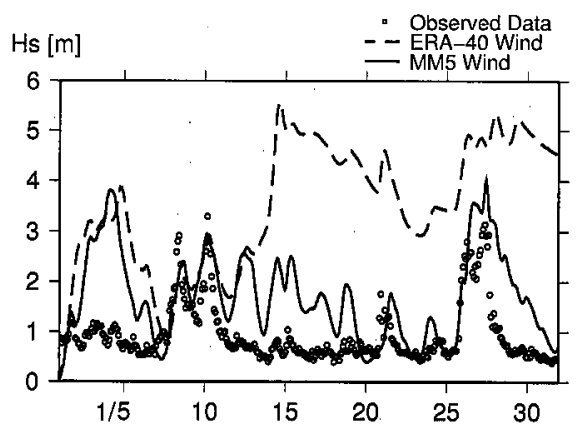

(a) 御前崎での有義波高変化（2001 年 1 月）

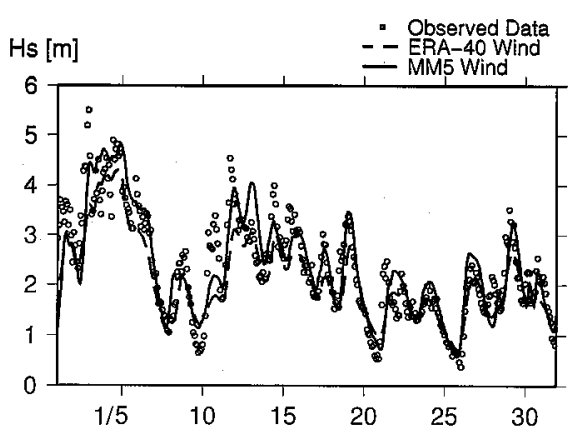

(b) 輪島での有義波高変化 (2001 年 1 月)

図-6 推算結果と観測值との比較 
用いて高解像度に解析している.ここではこの MM5 に よる海上風の高解像度化が波浪推算結果に及ほすす影響に ついて検討する。

図-4から図-6には，ERA-40の海上風デー夕を用い た波浪推算結果を破線で，MM5による海上風解析結果 を用いた推算結果 (実線)および観測結果（丸印）と合 わせて示している。これらの図から ERA-40を用いて 推算された有義波高は MM5 の解析結果を用いた場合や 観測結果に比べて大きな值を示していることがわかる. これは ERA-40の空間解像度が緯度経度方向とも 2.5 度と，日本列島を再現するには粗いため，特に沿岸域で は海岸線や周辺陸地の地形が十分には再現されず，海上 風が比較的強く評価されているためと考えられる。これ らの図の結果から日本列島沿岸域での波浪推算を実施す る際には ERA-40の海上風デー夕では不十分であり, 局地気像モデル MM5 などによる高解像度の海上風デー

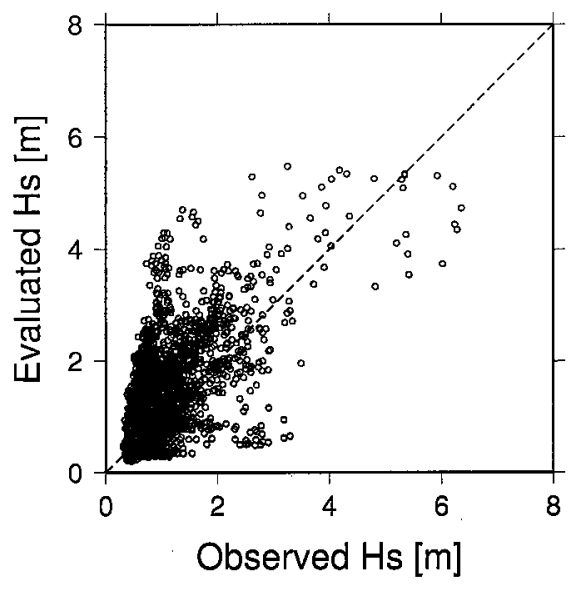

(a) 御前崎

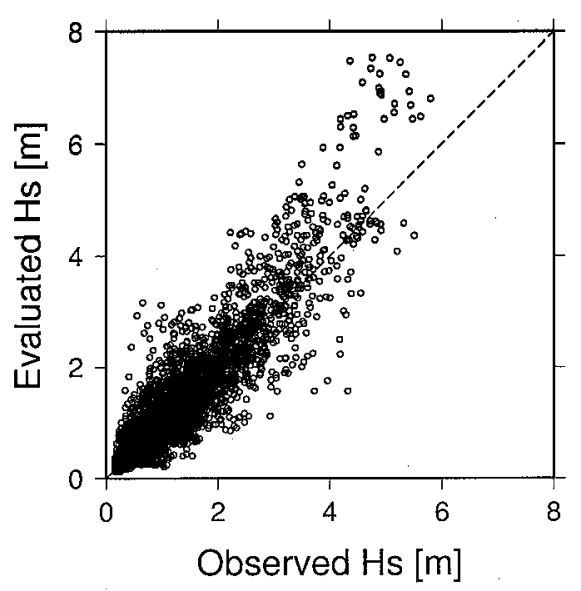

(b) 輪島

図-7 推算結果と観測值との比較(有義波高，2001 年通年)
夕を用意する必要があることがわかる.

\section{4. おわりに}

本研究では長期間の再解析気象データセット ERA-40 (ECMWF 40 Year Re-Analysis) を用いて約 45 年間に およぶ日本列島周辺域の長期波浪データベースを構築し た. ただし ERA-40の空間解像度は緯度・経度方向に 2.5 度と日本列島周辺域を対象とするには粗いため, 本 研究では局所気象モデル MM5を用いてより高解像度の 海上風を解析し，その結果を用いて第三世代波浪推算モ デルSWANにより波浪推算を行った。構築した波浪デ ータベースを観測結果と比較したところ, 台風来襲時を 含めこのデータベースは観測結果をほぼ再現しているこ とが確認できた。これらにより本研究では十分な精度を 有する波浪データベースを構築することができた。

謝辞：本研究では ECMWF (European Centre for Medium-Range Weather Forecasts）の全球再解析デー 夕 ERA-40 (ECMWF 40 Year Re-Analysis) および全 国海洋波浪情報網（ナウファス）のデータを使用しまし た.この ERA-40のデー夕は東京大学先端科学技術研 究センター梶野瑞王氏に提供して頂きました。ここに謝 意を表します. 本研究は科学研究費 (B)一般 18360236, (C)一般 18560496 による成果です.

\section{参 考 文 献}

川口浩二 ・橋本典明・鈴山勝之 (2002)：波浪推算值に基づく日 本沿岸波浪の出現特性について，海岸工学論文集，第 49 卷, pp. 216-220.

（独法）港湾灴港技術研究所: 全国港湾海洋波浪情報網（ナウ ファス）波浪観測データ, http://www.pari.go. $\mathrm{jp} / \mathrm{bsh} / \mathrm{ky}$-skb/kaisho/，参照 2007-05-18.

永井紀彦・小川英明·(2003): 全国港湾海洋波浪観測年 報 (NOWPHAS2001)，港湾空港技術研究所資料, No. 1041.

（財）日本気象協会 編 (2001): 月刊「気象」, 日本気象協会.

山口正隆・畑田佳男・松木太郎(1997): ECMWF 風を用いた長 期波浪推算システムの適用性の検討, 海岸工学論文集, 第 44 巻, pp. 241-245.

Booij,N.R., R.C.Ris and L.H.Holthuijsen (1999) : A third-generation wave model for coastal regions, Part I, Model description and validation, Journal of Geophisical Research, Vol. 104, No. C4, pp. 7649-7666.

Dudhia,J. (1993) :A nonhydrostatic version of the Penn State-NCAR Mesoscale Model; Validation tests and simulation of an Atlantic cyclone and cold front, Mon. Wea. Rev., Vol. 121, pp. 1493-1513.

Grell,G.A., J.Dudhia and D.R.Stauffer (1995) :A discription of the fifth-generation Penn State / NCAR Mesoscale Model (MM5), Tech. Note TN-398+IA, National Center for Atmospheric Research, Boulder, CO, 125p.

Uppala, S.M. et al. (2005) :The ERA-40 re-analysis, Quart. J. R. Meteorol. Soc., 131, 2961-3012. 